\title{
When Transgender Employees Come Out: Perceived Support and Cultural Change in the Transition Process
}

\author{
Lizabeth Kay Kleintop \\ Moravian College
}

Increased visibility of transgender people challenges employers to create inclusive workplaces for those who transition in the workplace. Previous studies and prescriptive works examined transitions with a focus on the transgender employees' side of the transition and the workplace policies used to assist them in their transitions. While leading to greater job satisfaction, transitions do not necessarily lead to a better fit in the organization for transgender employees. This paper discusses workplace transitions of transgender employees with respect to their co-workers and organizational culture which may need change to create a supportive and inclusive workplace.

Keywords: Transgender, Gender Identity, Workplace Transition, Gender, Transphobia, Discrimination

\section{INTRODUCTION}

Transgender people are more visible in society today than just a few years ago. The New York Times declared culture's transgender moment to be one of the 20 happenings of 2015 citing President Barak Obama's use of the word "transgender" in his State of the Union address, Caitlyn Jenner coming out in the bright lights of the media, and Andreja Pejic being the first openly transgender model to be the marketing face of a major makeup brand as examples (Tisak, 2015). Many more transgender people have come out publicly since then. The number of people transitioning, the ways people move across the boundaries of an unchosen gender category to a chosen category (Carter, 2014), familiarly known as coming out, is not counted in workplaces. With the increased visibility of transgender people, it is reasonable to expect the frequency of transitions in the workplace to have increased (Elejalde-Ruiz, 2016). Published studies and prescriptive works that examined those transitions generally focused on the transgender employees' side of the workplace experience when transitioning by examining their personal transition experiences and the workplace policies that were needed to assist them in their transitions.

Being open about one's status as a transgender person may lead to greater job satisfaction, but not necessarily make for a better fit within their place of employment nor to changes in discrimination they faced (Martinez, Sayer, Thoroughgood, Ruggs, \& Smith, 2017). Ruggs, Martinez, Hebl, and Law (2015) found that being open about one's transgender status, coming out at work, did not lead to lowered perceptions of discrimination in the workplace among transgender employees.

The purpose of this paper is to extend the understanding of workplace transitions by transgender employees so employers can create truly inclusive workplaces. Martinez et al (2017) pointed out that others' reactions to a transition in the workplace was important to the transitioning transgender employee's perception of organizational support. The existing literature on transgender people's 
experiences in the workplace, however, does not explain the effect of employer and co-workers attitudes and behaviors that could explain the psychological impact of perceived discrimination experienced by transgender employees. Perceptions of discrimination affect transgender employees' work and job satisfaction, turnover intentions, and emotional states all leading to increased turnover intent (Sawyer \& Thoroughgood, 2017; Thoroughgood, Sawyer, \& Webster, 2017). The lack of social support, workplace gender policing, personal safety threats, acquisition and advancement barriers, intersectional discrimination, intuited stigma, and lack of inclusive policies also were found to contribute to transphobia that created challenges to people transitioning at work (Mizock, Riley, Yuen, Woodrum, Sotilleo, \& Ormerod, 2017). Longer term solutions to reducing the impact of prejudice against transgender employees can only be enacted by employers (Thoroughgood, et al., 2017). Understanding co-workers attitudes about transgender individuals can lead to better transition policies and outcomes for employees and employers.

\section{DEFINING TRANSGENDER}

Gender identity is one's innermost concept of self as male, female, a blend of both or neither - how individuals perceive themselves and what they call themselves (The Human Rights Campaign [HRC], 2015a).

Everyone has a gender identity. Most people's gender identity is the same as the sex assigned to them at birth. The gender identity and/or expression of transgender people, though, is different from cultural expectations based on the sex they were assigned at birth (HRC, 2015a). Gender expression refers to external characteristics of individuals and their behaviors, including dress, grooming, and mannerisms that are socially identified with a particular gender (Cadrain, 2009). Being transgender does not imply any specific sexual orientation. Being transgender is not a mental illness, but being transgender can cause clinically significant distress (American Psychiatric Association, 2016).

Transgender is an umbrella term that describes a range of gender-variant identities (Williams, 2014). For the purposes of this paper, transgender refers to individuals who transition from female to male (FtM) or male to female $(\mathrm{MtF})$ gender identities and expressions.

Gender transition is the process which some transgender individuals go through to live in the gender with which they identify rather than the one assigned to them at their birth (The Human Rights Campaign [HRC], 2019). Transition may include hormone therapy, sex reassignment surgery, or other medical procedures. Not all those who identify as transgender go through the same process.

Gates (2011) estimated that $0.3 \%$ of the U.S. adult population is transgender though that number is believed to be an understatement. A later study, estimated that $0.6 \%$ of the U.S. adult population, or 1.6 million people, were transgender (Flores, Herman, Gates, \& Brown, 2016). Meerwijk and Sevelius (2017) estimated the size of the transgender population in the United States to be one million people based on a meta-regression analysis. Transgender people are difficult to count in part because of their perceived need to hide from social ostracism; also, government and other survey organizations don't ask if someone is transgender (Miller, 2015). Meerwijk and Sevelius (2017) suggested the estimates of the size of the population of transgender people will increase as inconsistencies in instruments used to count the transgender population are resolved.

\section{DOING GENDER AT WORK AND WORKPLACE TRANSPHOBIA}

"I've noticed that I don't have the same respect that I used to. I used to be able to be invited to meetings and people ask my opinion. Not anymore. My mailbox used to be full, not anymore" (Julie quoted in Budge, Tebbe, \& Howard, 2010, p. 384).

"I was in maintenance, and the person who was supposed to be my partner refused to work with me. . . . I contacted Legal Rights, and found out that there was nothing I could do. So I just kept my mouth shut, did what I had to do" (Gina quoted in Budge, et al., 2010, p. 384). 
"After my transition in 2012, I definitely noticed that men treat women differently in the workplace than they treat other men. In meetings, the guys didn't take me as seriously and didn't listen to my ideas as well as they had done previously. It sometimes helped to drop my voice pitch to a deeper tone when I needed to make a point, but that also lead to me feeling some dysphoria, which was uncomfortable" (Worthington, 2015).

In the weeks that followed [her coming out at work], Paul noticed subtle changes in her workplace relationships. She was left off an invitation to a birthday party. She showed up at the cafeteria where she'd often joined colleagues for meals to find no one there. "Probably what hurt the most was that I had been left kind of alone" (J. L. Paul quoted in Elejalde-Ruiz, 2016).

Transgender individuals may be targets of transphobia - "the motivating force for negative reactions to transgendered [sic] people that involve fear and disgust on the part of the observer [...] that is often manifest in the fear of personal acquaintances becoming transgendered [sic] or revulsion on learning one is transgendered [sic] or meeting a transgendered [sic] person" (Hill, 2002, cited in Rudin, Ruane, Ross, Farro, \& Billing, 2014, p. 722) ${ }^{1}$. Transphobia is based in gender expectations promulgated by society, social expectations of the roles and behaviors of women and men. Workplaces have a long history of embedding gender expectations related to the division of labor into hiring and promotion decision making (Acker, 1990; Schlit \& Connell, 2007). Traditional gender role expectations are unique predictors of antitransgender attitudes (Tebbe \& Moradi, 2012).

Transitioning is the action of living one's true gender identity in life, both inside and outside of work. Not all transgender people transition, but those who choose to transition do so to live in a manner consistent with their gender identity (Out \& Equal Workplace Advocate, 2014). Transgender people transition to reduce the stress of hiding their identity, be more productive at work, develop closer, more genuine relationships with colleagues, customers, and clients, build self-esteem from being known for who they really are, have authentic and open friendships with other transgender people, and become role models for others (Human Rights Campaign [HRC], 2015b).

\section{Workplace Discrimination and Transgender Employees}

A broad ranging set of discriminatory behaviors experienced by transgender people in the workplace include, but are not limited to, exclusion from certain jobs based on bona fide occupational qualifications, physical assault, verbal harassment and abuse, destruction of property, ridicule, homophobic jokes, unfair work schedules, workplace sabotage, restrictions to their career, resentment for "special treatment", religious intolerance, "deadnaming" or the use of former names or pronouns, bullying, ignoring, shunning, avoidance, sexual assault, coercive social and cultural domination, name-calling, and job loss (Budge, et al., 2010; Hill, 2009; Kirk \& Belovics, 2008).

Harassment and discrimination at work has a direct effect on transitioning employees' careers. Researchers conducting the National Transgender Discrimination Survey (NTDS) found that of the 70\% of transgender respondents who had a job and/or applied for a job in the year prior to the study, $67 \%$ were fired, not hired, or were denied a promotion (James, Herman, Rankin, Keisling, Mottet, \& Anafi, 2016). Forty-one percent of respondents who reported being fired, forced to resign, or denied a promotion believed it was due to discrimination because of their transgender status. Respondents also reported other mistreatment at work; $23 \%$ of respondents reported one or more experiences of information being shared about them that should not have been shared, negative job reviews, being forced to resign, being forced to use a restroom not consistent with their gender identity or not being able to work out an acceptable restroom situation, be required to present in the wrong gender, removal from direct contact with clients, customers, or patients, or being forced to transfer to another department (James, et al, 2016).

The fear of losing a job also motivated transgender people not to transition completely at work. Some $53 \%$ of respondents, reported hiding their gender identity at work and $47 \%$ of respondents said they did not ask their employer to refer to them with their correct pronouns (he, she, or they) because they feared discrimination; $66 \%$ of non-binary respondents avoided asking to be referred to by their correct pronouns (James, et al, 2016). More than one-quarter of respondents reported staying at a job that they would have preferred to leave because they feared encountering discrimination elsewhere. 
Respondents to the 2011 version of the NTDS who lost a job due to bias were more likely to have attempted suicide $(55 \%)$ in their lifetime than those who did not lose a job due to bias; the latter respondents reported a 38\% rate of attempted suicide in their lifetime (Grant, Mottet, Tanis, Harrison, Herman, \& Keisling, 2011). Those lifetime suicide percentages stand in stark contrast to the lifetime attempted suicide rate of the general population, reported as $4.6 \%$ by one source (Kessler, Borges, \& Walters, 1999).

Discriminatory behaviors of co-workers create significant legal risks and challenges to the successful transition of an employee in the workplace. Transgender employees have sued their employers for discrimination, harassment, and retaliation, including Walmart, Giant Foods, Starwood Hotels, Barnes \& Noble, and others (Brinkmann 2015; Covert, 2015; Fiorillo, 2015; Zillman, 2015). In Macy v. Department of Justice, the U.S. Equal Employment Opportunity Commission (Equal Employment Opportunity Commission [EEOC], 2012) held that discrimination against an individual because that person is transgender is discrimination because of sex and a violation of Title VII of the Civil Rights Act of 1964. Since that opinion, the EEOC has handled four appeals related to gender identity and four amicus briefs supporting the interpretation of Title VII put forth in Macy v. Department of Justice (Equal Employment Opportunity Commission, 2015). EEOC guidance to employers has continued to support the above actions (Mills, 2018). The United States Supreme Court heard oral arguments in October 2019 in R.G. \& G.R. Harris Funeral Homes Inc. v. Equal Employment Opportunity Commission to decide whether Title VII prohibits discrimination against transgender people based on (1) their status as transgender or (2) sex stereotyping as held by the EEOC (Supreme Court of the United States Blog, 2019). Avoiding legal entanglements involving discrimination is a significant motivation for employers to get transitions right (Wilkie, 2015).

\section{Transgender Challenges to Co-Workers' Perceptions of Gender}

Supportive organizations are those that take pride in their employees, compensate them fairly, and, especially within the context of transgender employee transitions, look after employees' needs (Randall, Cropanzano, Bormann, \& Birjulin, 1999). Employers looking to be supportive of employees transitioning at work need to consider both their co-workers and the workplace setting when planning transitions.

A person's gender identity as perceived by others is determined in a social process of authentication. Visual and behavioral cues are used by people to identify another's gender. Transgender people may be given different gender classifications than they themselves hold by those viewing them depending upon the type of interaction occurring. The social classification process mediates access to space and relationships based upon whether a context is culturally gender-integrated, gender-segregated, or heterosexual (Westbrook \& Schilt, 2014). In settings where men and women interact and are gender integrated, a transgender woman can be accepted as female based on their visual and behavioral presentation. In nonsexual, gender-segregated contexts, such as engineering jobs, gender assignment may require visual, behavioral, and biology-based criteria; a transgender woman in this context may not be accepted. Finally, in clear heterosexual contexts, such as restrooms, biology-based criteria apply; for transgender men gender is not typically enforced with violence in this context; it may for transgender women (Westbook \& Schlit, 2014, p. 51). West \& Zimmerman (1987, p. 136) refer to the challenge of this social process as doing gender - not always living up to normative conceptions of femininity or masculinity but engaging "in behavior at the risk of gender assessment".

Transgender people challenge this gender authentication process by being gender non-conforming. Their gender non-conformity challenges deeply held societal norms of a binary gender system that is reinforced by a multitude of social and regulatory processes (Rudin, et al., 2014, p. 723). Sex-segregated restroom facilities, a requirement of the International Building Code applied by many states and municipalities in the United States as their building code, send the message that there are only two possible forms of gender expression, though recent changes allow single-user facilities to be designated for either sex (International Code Council, 2017). The building code further requires that publicly accessible restrooms be marked with signage designating their use by sex not gender. Some of Brewster, Velez, Mennicke, \& Tebbe's (2014) respondents reported that where work environments required specific 
gender presentations such as uniforms or gendered spaces such as restrooms, transitions were more challenging. Restroom segregation creates a gender barrier by implicitly embedding the cultural norm of binary genders into businesses creating a challenge to co-workers acceptance of transgender individuals (Rudin, et al., 2014). Furthermore, cisgender males may be more likely to be concerned with restroom segregation. Stones (2017) found cisgender males to be more likely to express concern for women's safety in restrooms when discussing transgender females than cisgender females even though cisgender males do not normally use female restrooms. McCullough, Dispenza, Chan, \& Zeilgman (2019) found a relationship between male cisgender, heterosexual individuals and those holding conservative political ideology and increased levels of anti-transgender prejudice. Those authors suggested that transgender individuals threaten the gender norms of those individuals leading to higher levels of transphobia.

Transgender employees challenge the imprints, some conscious and some unconscious, of words, thoughts, attitudes and beliefs that people carry with them into the workplace, their worldviews, a framework or schemata of the world that allows people to understand new experiences by filtering information (Arbib, 2004; Hill, 2009; Robinson, van Esch, \& Bilimoria, 2017). Information that does not fit the schemata is determined to be an aberration. Co-workers can experience gaps between what they see happening in a transition, the experiences of transgender people, and their own experiences of life. These gaps challenge understanding and create anxiety and may lead to unconscious or conscious discrimination, harassment, misgendering, microaggressions, and bullying (Robinson, et al., 2017).

Violating the norms of gender identity results in cultural anxiety for cisgender employees that can lead to their discriminating against transgender co-workers even in workplaces that proclaim their inclusiveness. Schilt and Connell (2007) identified the ambiguity of gender assignments for transgender employees as a source of anxiety for co-workers. Priola, Lasio, De Simone, and Serri (2014) found informal or interpersonal discrimination to be the norm in self-proclaimed inclusive organizations they studied based on practices of silence, gossip, and derogatory comments made about LGBT employees. The cultures of those organizations prohibited openness about sexual identity while also enabling gender policing.

Gender policing refers to gender-related stigma communicated to transgender people verbally or nonverbally about expected gender behaviors, including a dress code, work roles, and restroom and locker room use (Mizock, Riley, Yuen, Woodrum, Sotilleo, \& Ormerod, 2018). Gender policing can result in active harassment, including verbal and physical abuse, ridicule, transphobic jokes, exclusion from jobs based on bona fide occupational qualifications, dead naming, and other actions from co-workers and managers that are meant to pressure transgender people to conform to gender roles (Budge, et al., 2010; Hill, 2009; Kirk \& Belovics, 2008; Mizock, et al, 2018).

Co-workers' anxiety can lead to resentment for what they perceive as special treatment for transitioning employees, open criticism of diversity policies, or more frequently, passive resistance with marginal cooperation, a lack of involvement, and excuse making with respect to diversity policies (Hill, 2009). The transitioning employee may also come to be the subject of microaggressions, commonplace, interpersonally communicated othering messages related to a person's perceived marginalized status (Nordmarken, 2014; Robinson, et al., 2017). Backlash may also be more overt and expressed as bullying, ignoring, shunning, avoidance, and acts of violence, physical and symbolic, in the workplace (Hill, 2009). Resistance and backlash may create an environment that puts not only the safety and well being of the transitioning employee at risk but also puts the organization at risk for legal action.

Proposition 1: Gendered work roles indicate low levels of organizational support for an employee to transition successfully in the workplace.

Proposition 2: The lack of non-gendered physical facilities indicates low levels of organizational support for an employee to transition successfully in the workplace.

Proposition 3: The greater the gap between co-workers' life experiences and their perceptions of a transgender employee's transition the less the perceived organizational support for the transition. 


\section{WORKPLACE TRANSITION PLANS AND CULTURAL CHANGE}

From an employer perspective a successful workplace gender transition demonstrates the organization's inclusiveness which is expected to lead to a productive, innovative, and creative workforce (Society for Human Resource Management [SHRM], 2017). A successful transition also demonstrates the organization's diversity climate, the extent to which the "organization values and integrates diversity and supports it through fair employment practices" (Singh, Winkel, \& Selvarajan, 2013).

Transgender employees in transition are looking not only to express themselves fully, but to do so in a psychological safe environment. Kahn (1990, p. 705) defined psychological safety as the "sense of being able to show and employ self without fear of negative consequences to self-image, status, or career". When an organization creates a psychologically safe environment, employees feel more "safe in taking risks of self-expression and engaging the process of change" (Kahn 1990, p. 708). Singh et al (2013) in a study of racially diverse work settings found that in a supportive diversity climate employees felt psychologically safe expressing their identities. They further linked positive perceptions of psychological safety to employee performance. Psychological safety is created within interpersonal relations, group dynamics, management style and processes, and organizational norms (Kahn, 1990).

The Human Rights Campaign [HRC] (2015c), Out \& Equal Workplace Advocates (2014), and the Society for Human Resource Management (SHRM, 2016; SHRM, 2017) provided recommendations to employers for managing the process for transgender employees who are transitioning, as do various authors (Sawyer \& Thoroughgood, 2017; Stirba, Goldstein, Gentili, Reynolds, Hill-Meyer, \& Scarborough, 2014; Walworth, 2003; Weiss, 2007). These recommendations often are incorporated into transition plans for transgender employees. The purpose of a transition plan is to guide the transition process for an individual within an organization to ensure legal compliance by preventing discrimination and establishing a talent environment maximizing the value of people regardless of who they are (Cadrain, 2009). The transition plan is a planned change document (Barclay \& Scott, 2006; Hill, 2009).

Organizations attempt to create predictable patterns of behaviors from employees (de Caluwé and Vermaak, 2003). Transition plans are created for transitioning employees to allow the organization to maintain predictability and have control over the process of transitioning. This control benefits both the transitioning employee and the organization by minimizing risks for both.

Failure of transition plans can create significant risks for employers. Those risks include decreased productivity of transitioning employees as they deal with harassment and mistreatment while remaining in the workplace, resignations of knowledgeable employees who do not want to continue to work in unsupportive environments creating a loss of competencies for the employer and costs for recruiting, hiring, and training new talent, and risks of legal actions by employees, former employees, and/or governmental organizations.

Recommendations of what should be included in a transition plan include acknowledgement of coworker concerns, restroom designation, dress codes, personal identification and records, health insurance, use of appropriate pronouns, as well as the roles and responsibilities of the transitioning employee, the employee's manager, and human resources (Cadrain, 2009, Taylor, Burke, Wheatley, \& Sompayrac, 2011). These recommendations are largely concerned with the management style and processes of organizations which, when supportive, enhance psychological safety (Kahn, 1990).

Taranowski (2008), Sawyer and Thoroughgood (2017) and others identified training programs for coworkers of the transitioning employee as an important part of the transition plan for explaining gender identity, transitions, and expectations of behavior in the workplace. SHRM (2016) identified training programs offered by employers as important anti-discrimination tools that may need to be updated to include transgender employees'. The focus of the training, according to SHRM, needs to be on employees understanding "the organization's expectations when a transgender employee is joining their ranks or when a current employee is in gender transition" (SHRM 2016). This form of training is an educational approach as defined by Tompkins, Shields, Hillman, and White (2015). The focus of this training is on creating supportive group dynamics that lead to perceived psychological safety through lessening of all employees' conscious and unconscious anxieties about the transition (Kahn, 1990). 
The choice of training approaches enacted as part of the transition process may be important. Tompkins, et al. (2015) found that the approach taken to educate individuals about transgender people made a difference in the attitudes they expressed about transgender people after training. An approach to humanizing transgender people with first person narratives and perspective-taking tasks versus an educational approach involving a slide show and video talk by an expert about gender identity disorder led to different outcomes with respect to subjects' attitudes toward transgender people. Subjects participating in the humanizing condition were much more likely to demonstrate more favorable attitudes than those who participated in the educational approach; those in the educational approach endorsed greater levels of transphobia after the intervention than before (Tompkins, et al., 2015). McCullough et al. (2019) found a relationship between previous contact of cisgender, heterosexual individuals with gay men and lesbians with lower levels of anti-transgender prejudice. They suggested that creating dialogue with cisgender, heterosexual employees about transgender people's experiences may lead to lower antitransgender prejedice through greater understanding.

In an experimental study with an imagined intergroup contact as the key manipulation, Moss-Racusin and Rabasco (2018) found that humanizing a newly hired transgender employee to co-workers resulted in increased perceived hireability of the transgender employee, self-other overlap, and perspective taking, that is looking at a situation from a viewpoint that is different from one's usual viewpoint (American Psychological Association, 2018). The levels of hireability, self-other overlap and perspective taking were found to be at a level similar to those of a newly hired cisgender coworker, although the transgender target was still viewed as less likable than the cisgender target. These findings also suggest the effort to humanize transgender people will have positive outcomes for the workplace.

Proposition 4: A training program that combines employers' expectations of employees behavior in a transition with humanization will result in more favorable attitudes toward transgender people than a training program focused solely on employer expectations.

\section{Transitions Are for Co-Workers, Too}

Transitions are usually considered to be about the transgender person, the one transitioning. Employers often create transition plans that are meant to create a smooth, uneventful process for both the transitioning individual and the organization. There may be acknowledgement of co-workers in the transition planning, such as when a letter or email about the transition is sent out to employees. However, unless co-workers of a transgender person had already experienced a transition and know what to expect, the transition is about them, too. Brewster et al (2014) noted that creating connections and social interactions prior to transition appeared to be more important to the transition experience than the tasks traditionally included in transition plans -- changing names, email addresses, and the like. Co-workers need information and training to know what to expect and how to behave. In other words, co-workers need to prepare for the transition, too.

When focused on training about what it is like to be a transgender person and using only questionand-answer sessions as a training technique for co-workers, transition planning for transgender people coming out in the workplace lacks deep examination of the anxieties experienced by co-workers also undergoing transition. The suggestions and examples provided by HRC (2015c), Out \& Equal Workplace Advocates (2014), SHRM (2017), Weiss (2007), Walworth (2003), Stirba, et al. (2014) and others provide recommendations to employers for managing the process for transgender employees coming out. Those recommendations, however, do not include close examination of cultural norms that elicit coworkers' responses to transitioning employees. Employers are likely to take the path expressed by Ms. Connie Summers, Cultural Diversity and Inclusion Manager at Boeing, "we have no expectation of changing people's minds, but we do ask them to change their behaviors" (Cadrain, 2009).

Behaviors may be changed but in the challenge to cultural norms made by gender variant, transgender employees, the anxieties of co-workers may be raised. Change agents may be ill prepared to handle the backlash of gender panic on the part of co-workers if it is unplanned for and be unable to assist in 
overcoming resistance. Understanding resistance to a transition can be used as a starting point for overcoming anxiety if it is anticipated as part of the planning process (Hill, 2009).

NTDS results discussed above suggest that there can be significant failures in workplace transition plans that result in discrimination and harassment being experienced by the transitioning employee with consequent impacts on the organization, as well as the transitioning employee. Transition plans focus on changing observable employee behaviors by using diagnostic tools to affect change in the behaviors of employees in the workplace but not non-observable attitudes employees bring with them into the workplace. The diagnostic tools tend to focus on observable facts and objects within the business treating the business as a closed system and downplaying the interchange between the business and its environment (de Caluwé and Vermaak, 2003).

Change agents involved with a transition in the workplace face the problem of encouraging the organization to work toward establishing a safe climate for transgender employees while also coping with backlash from people who resist giving transgender people full equality (Hill, 2009). Schilt and Connell (2007) also suggested that the co-workers of transitioning employees may face anxiety about how to properly respond to a transitioning employee. Change agents are faced with two transitions - that of the transgender employee and that of their co-workers. Developing a program of training for co-workers that addresses gender issues could allow change agents to supply new meaning and perspective to the coworkers going through transition.

Proposition 5: The more change agents incorporate an understanding of co-workers' perceptions of transgender people into transition plans, the greater the levels of organizational support that will be perceived by transitioning employees.

\section{A Cultural Approach to Transition Plans}

Transition plans are created in organizations that have complex cultures embedded within a broader social culture that is antithetical to switching gender or to the fluidity of gender identity as evidenced by data on harassment and discrimination. In the United States, transgender people are targets of harassment and discrimination at very high rates, including physical assault and sexual violence, being fired, not hired, or denied promotions, homelessness, abuse by police, and discrimination in healthcare (Grant, et al., 2011; James, et al., 2016). Using a cultural approach to viewing change can improve transition plans and outcomes for both the transitioning employees and organizations.

A cultural approach to change assumes people interact with each other within organizations using their own codes of behavior in a self-organization process that evolves behavioral patterns through development and learning (de Caluwé and Vermaak, 2003, p. 49). Employees act within the prescribed organizational norms that result. They feel psychologically safe when their behaviors do not call into question the habitual patterns of thought and behavior expected in the workplace (Kahn, 1990). Change agents are observers of the process of change and are actors who supply meaning, perspective, remove obstacles, and empower others (de Caluwé and Vermaak, 2003). Change agents must be astute participant observers analyzing underlying drivers and norms while wisely choosing interventions to create conditions so that employees are engaged and productive.

To be active participants in the transition process for transgender employees, change agents need to understand gender identity within the context of an organization's culture. SHRM (2016) suggested that change agents need to develop a "culture of appreciation of differences" that includes treating all employees fairly. Understanding how co-workers of transitioning employees define and live gender identity will improve change agents' understanding of the meaning of gender within businesses and allow them to intervene appropriately to achieve the goals of transition plans -- a safe, successful transition for the employee and reduced legal and other risks to the organization.

Proposition 6: The more change agents understand co-workers' perceptions of gender in the workplace the more successful the transition process will be for transgender employees. 


\section{CONCLUSIONS}

There is little research on the implementation of transition plans for transgender employees. Publications by professional and advocacy organizations focus on workplace policies for inclusion and the process of supporting a transitioning employee largely to avoid legal entanglements and to advertise the inclusiveness of the organization. These activities are valuable for transitioning employees to perceive support from their employers. But they may not be sufficient. The recommendations do not account for the cultural context of organizations.

Practitioners should also pay attention to the cultural context, both internal and external to the organization, when developing transition plans to create a broad perception of organizational support. Practitioners should understand that transition is a series of steps, often small, for a transgender person that are intense and leading to a new personal equilibrium (Carter, 2014). Practitioners also need to understand that while transition is a series of small steps for the transgender person these steps may appear as large and threatening to co-workers. It is not enough to tell co-workers to change their behavior. Change agents must help co-workers to understand their own attitudes so that their behaviors become inclusive behaviors.

Researchers face a different challenge. Research on transitions in the workplace has focused on transgender employees, what they experienced, what they felt, and the outcomes, often using interview methods (see for example, Schilt, 2006, Dietert \& Dentice, 2009, Dispenza, Watson, Chung, \& Brack, 2012, and Priola, et al., 2013). Barclay and Scott (2006) conducted a case study of one individual transitioning in the workplace, including interviews with managers, HR staff, and others. While important first steps those studies are insufficient for fully understanding what happens in transition processes.

Further research needs to examine the whole transition process. The methods used in previous research leave out the experiences of co-workers and are not sufficiently robust to allow a clear understanding of the complete process. Researchers looking at gender transition in the workplace need to apply methods that allow them to see into the transition process of co-workers, as well as that of transgender employees.

A more clear understanding of transition and its meaning for both transgender employees and coworkers will provide more options for practitioners to use as they develop transition plans for transgender employees and work through the process with them. Such research will also give a more complete picture of what steps and activities are needed to create truly inclusive business organizations, as well as assist practitioners in managing the risks businesses face when an employee transitions.

\section{ENDNOTE}

1. Transgender is an adjective. Transgendered inappropriately makes a verb out of an adjective. Until about the year 2000, transgendered was an accepted usage. Today many transgender people consider the use of transgendered to be offensive since it suggests that being transgender is something that was done to them. 


\section{REFERENCES}

Acker, J. (1990). Hierarchies, jobs, bodies: A theory of gendered organizations. Gender \& Society, 4, 139-158.

American Psychiatric Association. (2016). What Is gender dysphoria? Retrieved from https://www.psychiatry.org/patients-families/gender-dysphoria/what-is-gender-dysphoria

American Psychological Association. (2018). Perspective taking. Retrieved from https://dictionary.apa.org/perspective-taking

Arbib, M. (2006). Schemas. In R. L. Gregory (Ed.), The Oxford Companion to the Mind (2nd ed.). Oxford University Press. Retrieved from http://www.oxfordreference.com/view/10.1093/acref/9780198662242.001.0001/acref9780198662242-e-750

Barclay, J.M., \& Scott, L.J. (2006). Transsexuals and workplace diversity: A case of "change" management. Personnel Review, 35, 487-502.

Brewster, M. E., Velez, B. L., Mennicke, A., \& Tebbe, E. (2014). Voices from beyond: A thematic content analysis of Transgender employee's workplace experiences. Psychology of Sexual Orientation and Gender Diversity, 1(2), 159-169.

Brinkman, P. (2015, July 10). Starwood hotels battles transgender woman's discrimination lawsuit. Orlando Sentinel. Retrieved from https://www.orlandosentinel.com/business/os-transgenderstarwood-20150710-story.html

Budge, S.L., Tebbe, E.N., \& Howard, K.A.S. (2010). The work experiences of transgender individuals: Negotiating the transition and career decision-making processes. Journal of Counseling Psychology, 57, 377-393

Cadrain, D. (2009, October). Accommodating sex transformations. HR Magazine, 59-62.

Carter, J. (2014). Transition. Transgender Studies Quarterly, 1, 235-237

Covert, B. (2015, October 14). Transgender woman sues Walmart, manager she says harassed and then fired her. ThinkProgress. Retrieved from https://thinkprogress.org/transgender-woman-sueswalmart-manager-she-says-harassed-and-then-fired-her-179bea9b9ab/

de Caluwé, L., \& Vermaak, H. (2003). Learning to Change: A Guide for Organization Change Agents. Thousand Oaks, CA: Sage Publications

Dietert, M., \& Dentice, D. (2009). Gender identity issues and workplace discrimination: The transgender experience. Journal of Workplace Rights, 14, 121-40.

Dispenza, F., Watson, L.B., Chung, Y.B., \& Brack, G. (2012). Experience of career-related discrimination for female-to-male transgender persons: A qualitative study. The Career Development Quarterly, 60, 65-81

Elejalde-Ruiz, A. (2016, January 9). How companies accommodate transgender employees — and their colleagues. The Chicago Tribune. Retrieved from http://www.chicagotribune.com/business/cttransgender-workplace-0110-biz-20160109-story.html

Equal Employment Opportunity Commission. (2012). Macy v. Department of Justice, Appeal No. 0120120821.

Equal Employment Opportunity Commission. (2015). Fact Sheet: Recent EEOC Litigation Regarding Title VII \& LGBT-Related Discrimination. Retrieved from http://www.eeoc.gov/eeoc/litigation/selected/lgbt_facts.cfm

Fiorillo, V. (2015, November 12). Trans man sues Giant, says store tried to force him to wear bosomy female uniform. Philadelphia Magazine. Retrieved from http://www.phillymag.com/gphilly/2015/11/12/trans-man-sues-giant/\#ZvCfJKmuTbBs1xJ6.99

Flores, A. R., Herman, J. L., Gates, G. J., \& Brown, T. N. T. (2016). How Many Adults Identify as Transgender in the United States? Los Angeles, CA: The Williams Institute, UCLA School of Law. Retrieved from https://williamsinstitute.law.ucla.edu/wp-content/uploads/How-ManyAdults-Identify-as-Transgender-in-the-United-States.pdf 
Gates, G. J. (2011). How Many People are Lesbian, Gay, Bisexual, and Transgender? Los Angeles, CA: The Williams Institute, UCLA School of Law. Retrieved from http://williamsinstitute.law.ucla.edu/wp-content/uploads/Gates-How-Many-People-LGBT-Apr2011.pdf

Grant, J. M., Mottet, L. A., Tanis, J., Harrison, J., Herman, J. L., \& Keisling, M. (2011). Injustice at Every Turn: A Report of the National Transgender Discrimination Survey. Washington: National Center for Transgender Equality and National Gay and Lesbian Task Force.

Hill, D. B. (2002). Genderism, transphobia, and gender bashing: A framework for interpreting antitransgender violence, in Wallace, B. and Carter, R. (Eds.), Understanding and dealing with violence: A multicultural approach (pp. 113-136). Thousand Oaks, CA: Sage

Hill, R. J. (2009). Incorporating queers: Blowback, backlash, and other forms of resistance to workplace diversity initiatives that support sexual minorities. Advances in Developing Human Resources, 11(1), 37-53

International Code Council Inc. (2017). 2018 International Building Code. Retrieved from https://codes.iccsafe.org/public/document/IBC2018

James, S. E., Herman, J. L., Rankin, S., Keisling, M., Mottet, L., \& Anafi, M. (2016). The Report of the 2015 U.S. Transgender Survey. Washington, DC: National Center for Transgender Equality.

Kahn, W. A. (1990). Psychological conditions of personal engagement and disengagement at work. Academy of Management Journal, 33(4), 692-724.

Kessler, R. C., Borges, G., \& Walters, E. E. (1999). Prevalence of and risk factors for lifetime suicide attempts in the National Comorbidity Survey. Archives of General Psychiatry, 56(7), 617-626.

Kirk, J., \& Belovics, R. (2008). Understanding and counseling transgender clients. Journal of Employment Counseling, 45, 29-43.

Martinez, L. R., Sayer, K. B., Thoroughgood, C. N., Ruggs, E. N., \& Smith, N. A. (2017). The importance of being "Me": The relation between authentic identity expression and transgender employees' work-related attitudes and experiences. Journal of Applied Psychology, 102, 215-226.

McCullough, R., Dispenza, F., Chang, C. Y., \& Zeligman, M. R. (2019). Correlates and predictors of anti-transgender prejudice. Psychology of Sexual Orientation and Gender Diversity. Advance online publication. http://dx.doi.org/10.1037/sgd0000334

Meerwijk, E.L., \& Sevelius, J.M. (2017). Transgender population size in the United States: A metaregression of population-based probability samples. American Journal of Public Health, 107(2), e1-e8. Retrieved from https://www.ncbi.nlm.nih.gov/pmc/articles/PMC5227946/

Miller, C. C. (2015, June 8). The search for the best estimate of the transgender population. The New York Times. Retrieved from http://www.nytimes.com/2015/06/09/upshot/the-search-for-the-bestestimate-of-the-transgender-population.html?_r $=0$

Mills, K. A. (2018). EEOC will not tolerate transgender employee discrimination. American Bar Association. Retrieved from https://www.americanbar.org/groups/litigation/committees/youngadvocates/practice/2016/083016-eeoc-will-not-tolerate-transgender-employee-discrimination/

Mizock, L., Riley, J., Yuen, N., Woodrum, T. D., Sotilleo, E. A., \& Ormerod, A. J. (2017). Transphobia in the workplace: A qualitative study of employment stigma. Stigma and Health, 3, 275-282.

Moss-Racusin, C. A. (2018). Reducing gender identity bias through imagined intergroup contact. Journal of Applied Psychology. 48:457-474. doi:10:1111/jasp.12525

Nordmarken, S. (2014). Microaggressions. Transgender Studies Quarterly, 1, 129-134.

Out \& Equal Workplace Advocates. (2014). Workplace gender identity and transition guidelines. Retrieved from http://outandequal.org/app/uploads/2016/09/Transition-Guidelines-FullEdition.pdf

Priola, V., Lasio, D., De Simone, S., \& Serri, F. (2014). The sound of silence. Lesbian, gay, bisexual and transgender discrimination in 'Inclusive Organizations'. British Journal of Management, 25, 488502. 
Randall, M.L., Cropanzano, R., Bormann, C.A., \& Birjulin, A. (1999). Organizational politics and organizational support as predictors of work attitudes, job performance, and organizational citizenship behavior. Journal of Organizational Behavior, 20, 159-174.

Robinson, M. J., van Esch, C., \& Bilimoria, D. (2017). Bringing transgender issues into management education: A call to action. Academy of Management Learning \& Education, 16, 300-313.

Rudin, J., Ruane, S., Ross, L., Farro, A., \& Billing, T. (2014). Hostile territory: employers' unwillingness to accommodate transgender employees. Equality, Diversity and Inclusion: An International Journal, 33, 721-734.

Ruggs, E. N., Martinez, L. R., Hebl, M. R., \& Law, C. L. (2015). Workplace “trans"-actions: How organizations, coworkers, and individual openness influence perceived gender identity discrimination. Psychology of Sexual Orientation and Gender Diversity, 2, 404-412.

Sawyer, K., \& Thoroughgood, C. (2017). Gender non-conformity and the modern workplace: New frontiers in understanding and promoting gender identity expression at work. Organizational Dynamics, 46, 1-8.

Schilt, K. (2006). Just one of the guys? How Transmen make gender visible at work. Gender \& Society, 20, 465-490.

Schilt, K., \& Connell, C. (2007). Do workplace gender transitions make gender trouble? Gender, Work and Organization, 14, 596-618.

Singh, B., Winkel, D.E., \& Selvarajan, T.T. (2013). Managing diversity at work: Does psychological safety hold the key to racial differences in employee performance? Journal of Occupational and Organizational Psychology, 86, 242-263.

Society for Human Resource Management. (2016, September 28). Employing transgender workers.

Retrieved from http://www.shrm.org/templatestools/toolkits/pages/employingtransgenderworkers.aspx

Society for Human Resource Management. (2017, June 5). Managing gender transition in the workplace. Retrieved from https://www.shrm.org/resourcesandtools/tools-andsamples/toolkits/pages/managinggendertransitionintheworkplace.aspx

Stirba, J. L., Goldstein, Z. G., Gentili, C., Reynolds, H. M., Hill-Meyer, T., \& Scarborough, D. (2014). Employment. In L. Ericson-Schroth (Ed.), Trans Bodies, Trans Selves: A Resource for the Transgender Community, (pp. 155-173). New York: Oxford University Press

Stones, R. J. (2017). Which gender is more concerned about transgender women in female bathrooms? Gender Issues, 34, 275-291.

Supreme Court of the United States Blog. (2019). R.G. \& G.R. Harris Funeral Homes Inc. v. Equal Employment Opportunity Commission. Retrieved from https://www.scotusblog.com/casefiles/cases/r-g-g-r-harris-funeral-homes-inc-v-equal-opportunity-employment-commission/

Taranowski, C.J. (2008). Transsexual employees in the workplace. Journal of Workplace Behavioral Health, 23, 467-477.

Taylor, S., Burke, L. A., Wheatley, K., \& Sompayrac, J. (2011). Effectively facilitating gender transition in the workplace. Employee Responsibilities and Rights Journal, 23, 101-116. doi:10.1007/s10672-010-9164-9

Tebbe, E. N., \& Moradi, B. (2012). Anti-transgender prejudice: A structural equation model of associated constructs. Journal of Counseling Psychology, 2, 251-261.

The Human Rights Campaign. (2015a). Sexual orientation and gender identity definitions. Retrieved from http://www.hrc.org/resources/sexual-orientation-and-gender-identity-terminology-and-definitions

The Human Rights Campaign. (2015b). Coming out in the workplace as transgender. Retrieved from http://www.hrc.org/resources/coming-out-in-the-workplace-as-transgender

The Human Rights Campaign. (2015c). Transgender inclusion in the workplace: Recommended policies and practices. Retrieved from http://www.hrc.org/resources/transgender-inclusion-in-theworkplace-recommended-policies-and-practices

The Human Rights Campaign. (2019). Transgender FAQ. Retrieved from https://www.hrc.org/resources/transgender-faq\#4 
Thoroughgood, C. N., Sawyer, K. B., \& Webster, J. R. (2017). What lies beneath: How paranoid cognition explains the relations between transgender employees' perceptions of discrimination at work and their job attitudes and wellbeing. Journal of Vocational Behavior, 103, 99-112.

Tisak, T. (2015, December 11). Twenty things that happened for the first time in 2015. The New York Times. Retrieved from http://www.nytimes.com/2015/12/11/opinion/twenty-things-thathappened-for-the-first-time-in-2015.html

Tompkins, T. L., Shields, C. N., Hillman, K. M., \& White, K. (2015). Reducing stigma toward the transgender community: An evaluation of a humanizing and perspective-taking intervention. Psychology of Sexual Orientation and Gender Diversity, 2, 34-42.

Walworth, J. (2003). Transsexual workers: An employer's guide. Bellingham, WA: Center for Gender Sanity.

Weiss, J. T. (2007). Transgender workplace diversity: Policy tools, training issues and communication strategies for HR and legal professionals. North Charleston, SC: BookSurge Publishing.

West, C., \& Zimmerman, D. H. (1987). Doing gender. Gender and Society, 1, 125-151.

Westbrook, L., \& Schlit, K. (2014). Transgender people, gender panics, and the maintenance of the sex/gender/sexuality system. Gender \& Society, 28, 32-57.

Wilkie, D. (2015). Ignorance about LGBTQ issues=a lawsuit waiting to happen. Retrieved January 14, 2019, from http://www.shrm.org/hrdisciplines/diversity/articles/pages/lgbtq-inclusion-.aspx

Williams, C. (2014). Transgender. Transgender Studies Quarterly, 1, 232-234.

Worthington, E.J. (2015, December 29). Posting to Facebook group, Association for Transgender Professionals. Retrieved from https://www.facebook.com/groups/AssocTransProfessionals/

Zillman, C. (2015, May 8). Barnes \& Noble is latest retailer to face transgender discrimination lawsuit. Fortune. Retrieved from http://fortune.com/2015/05/07/barnes-noble-transgender-lawsuit/ 